\title{
The eco-unit settlement adapted to the vernacular culture: a case study of dwelling design in the Chaoshan area of Guangdong Province, China
}

\author{
Y. Z. Wang ${ }^{1,2}$ \& Y. T. Chen ${ }^{3}$ \\ ${ }^{1}$ Department of Civil Engineering, Shantou University, China \\ ${ }^{2}$ Huazhong University of Science and Technology, China \\ ${ }^{3}$ Shantou Institute of Architectural Design, China
}

\begin{abstract}
Chaoshan is a Chinese term that is used to describe a unique linguistic and cultural region located in eastern Guangdong, which is a south-eastern province of China. This is a unique region with its own culture that is quite different from its neighbours in the other areas of Guangdong, as well as the rest of China. Because there is a cultural uniqueness in this region, if the eco-architecture with some of its advanced and well-recognised eco-tech features does not respect the existing vernacular culture, it will not be accepted by the local residents. It is very important to find a suitable design of eco-architecture that will truly match the tradition. With an extensive investigation and study of the local culture, we find that the concepts of "compact", "sharing", and "autogenous" are best to describe the characteristics of the vernacular culture. To account for these characteristics, we proposed the mode of an "eco-unit settlement" in dwellings that are in harmony with nature in our design process. Using an "eco-unit settlement", our design of a hillside dwelling in the form of a Lo Shu Square received first prize in an architecture design competition in Guangdong Province in 2006. It has also become one of the programme designs that the government recommends to those residents who are going to build houses themselves. In the present paper, how the dwelling design of the "eco-unit settlement" adapts to the vernacular culture of the Chaoshan area will be discussed.
\end{abstract}

Keywords: vernacular culture, Chaoshan area, eco-unit settlement, dwelling design. 


\section{Introduction}

Eco-architecture is being promoted in the Guangdong province and throughout China as a component of the policy that was established in order to achieve sustainability [1]. The rationale for its implementation relies heavily on a set of benefits from the conservation of natural resources, which are adapted to the regional cultural identity and the customs of the local residents. Considering some of the common ecological technologies, such as solar energy, water recycling, and others, to duplicate and apply them towards residential use would be unacceptable for some people due to the large differences with the vernacular culture and prohibitive high cost.

From a technical and academic point of view, because of the benefits, the residential use of eco-technologies can be promoted easily. However, this is not the case for the average residential house, and is only relevant for the construction of expensive housing in the centre of large cities. The ecoarchitecture that will meet the real needs of the local people in this developing region is still very limited. The use of eco-tech in houses still remains to be implemented in the Chaoshan area. Therefore, we need to approach these dwellings with the appropriate ecological design.

The purpose of the present paper is to explore a suitable form of ecoarchitecture in the Chaoshan area that adapts to the vernacular culture. This paper will also focus on three aspects. The first and foremost of these is to understand the characteristics of vernacular culture, followed by the search for the adaptability of the existing eco-tech to the vernacular culture of the Chaoshan people, and lastly our residential design, which is based on the model of an "ecounit settlement" and a set of strategies of design, will be discussed.

\section{Vernacular culture in the Chaoshan area}

\subsection{Chaoshan area}

In southern China's Guangdong province, the south-eastern region, which is called the "Chaoshan area", appears to be a very specific and mystical land to the people living outside of this region. The Chaoshan area is known for its long history, encompassing three cities, including Shantou city, Chaozhou city, and Jieyang city. The land area is approximately 10,000 square kilometres and has a population of approx. 14 million. This area of land occupies only one-thousandth of China, but it has 1 per cent of the country's total population, which is almost equal to one-third of the world's Chinese overseas whose hometown is Chaoshan [2]. The Tropic of Cancer crosses this area, where the land is full of fertile fields, and is similar to other regions in southern China due to the role of the "air conditioner" provided by the South China Sea.

\subsection{Unique vernacular culture}

The Chaoshan area developed its unique vernacular culture by being shaped by its geographical environment, natural resources, history, and religion. The 
vernacular culture has a major influence not only locally but also abroad. For the local culture, whatever the achievements, or the outstanding figures in science, technology, commerce, and other subjects, they are all considered with a distinctive and regional culture imprint. Its cultural character has always been regarded as an important cause for the development of this region.

\section{Adaptation to the vernacular culture of eco-tech}

In the Chaoshan area, the impact of this regional culture is so far-reaching that we can find the core ecological concept from the cultural elements with a careful investigation of the customs, eco-experience of folk house construction, as well as the relationship between daily life and the natural environment. In the present investigation, we will consider and choose the appropriate technologies that can adapt to the Chaoshan culture.

\subsection{Value conception of the environment in customs and daily life}

\subsubsection{Intensive cultivation}

"Intensive cultivation" is a concept from agriculture in this region. It means conserving land resources and creating for detail. This concept is prominently reflected through their customs and daily life in the Chaoshan area. Due to the contradiction between limited arable resources and a dense population, land is always insufficient. According to the 2007 statistics, Shantou City is only using 106 square metres of cultivated land per capita, which is only $11 \%$ of the national average, 34\% of the province's average, and far below the United Nations Food and Agriculture determined per capita level of arable land of 533 square metres [3]. The Chaoshan area is so crowded that the land is one of its most important, yet vulnerable, resources. Under the condition of scarcity of land resources, intensive cultivation becomes the inevitable choice of Chaoshan residents to survive.

\subsubsection{Group solidarity}

Emphasising family honour makes the Chaoshan area very impressive in modern society and particularly overseas. Since the Chaoshan area was regarded as wild land in ancient times, its residents are immigrants from the central plains. People have always had to rely on the power of establishing a family for survival and development. This process is very difficult and, therefore, it should be cherished. "Family" represents unity and a sense of security. Generations have been inspired to work hard and love their homes. They lived in units of clans in order to form a large centred courtyard surrounded by closed buildings, a type of "compact enclosure" residence as the basic image of traditional houses, Figs. 1 and 2. These traditional family houses represent a "shrine" - as a family monument - that is a place where Chaoshan locals can perform their religious ceremonies. 


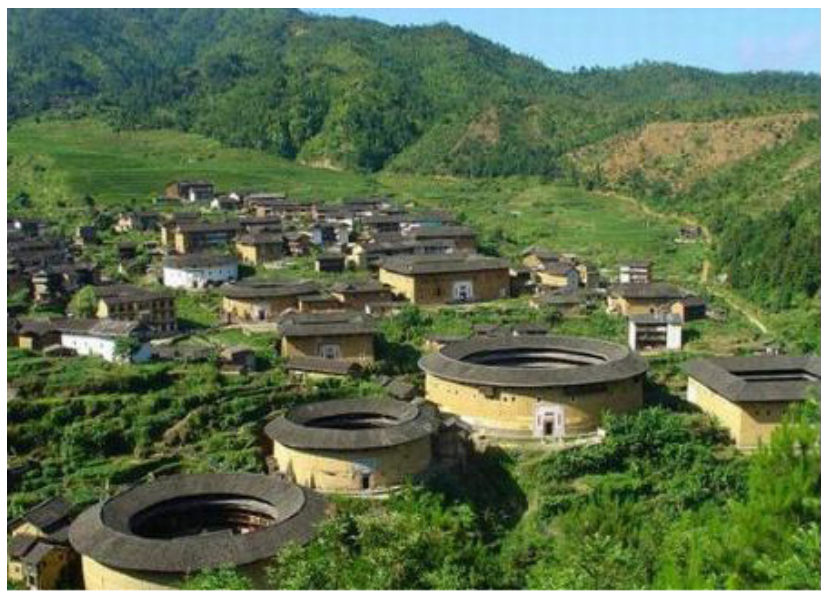

Figure 1: $\quad$ A residential area of Tulou in Chaozhou.

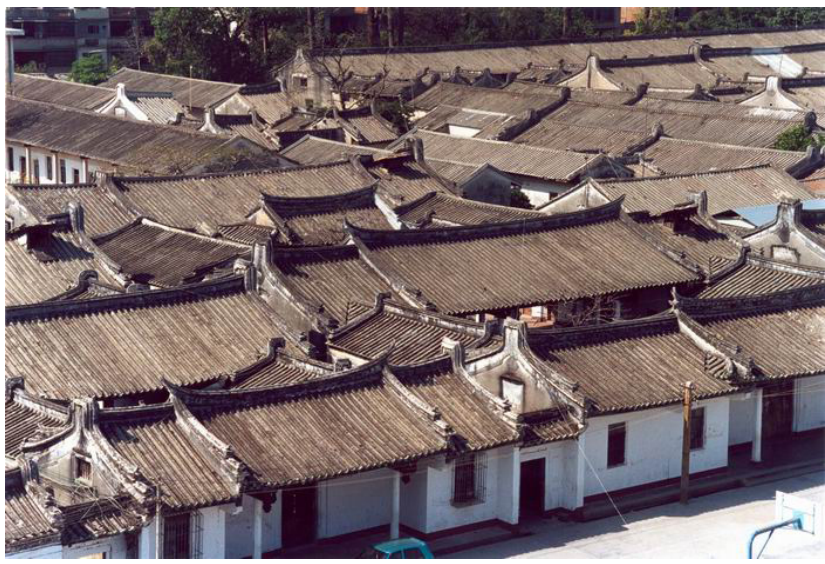

Figure 2: $\quad$ Residential group of the "house package" type in Shantou.

\subsection{Ecological experience of traditional dwellings}

From the existing traditional dwellings of vernacular culture, several of the ecological technology ideas are compatible with the traditional concepts [5]. When a traditional dwelling was planned, the occupation of the land and the use of space should be carefully calculated in order to select the best locations and orientation. Its "compact enclosure" design enabled the people who were living together to share resources, and to take advantage of an efficient structure in order to achieve natural ventilation and lighting. As a result of this design, it helped to provide low-cost housing in harmony with nature. 


\subsection{Characteristics of combining eco-tech with culture}

Through the observation of the vernacular culture, we can characterise the type of eco-tech into three concepts, which are "compact", "sharing", and "autogenous". "Compact" means the accumulation of space and the conservation of resources; "sharing" means that the residents can share the cost and benefits; "autogenous" means that the people can coexist with their natural environment without requiring too much power. "Compact", "sharing", and "autogenous" are the three core characteristics of combining eco-tech with the local culture in the Chaoshan area currently $[2,4,6]$.

\section{A residential design based on "eco-unit settlement"}

In regards to the previously described concepts with some ecological technologies, we propose the following concept model for the Chaoshan region, in turn calling it an "eco-unit settlement". The main principles of our model are the following:

1) The individual home is the section of a unit. The standard eco-unit is subdivided into nine sections so that large families can all live together in neighbouring homes. Every household not only has its own utilities, but also shares the environment and facilities with other households within the unit;

2) Each unit uses eco-tech not only in the individual homes but also in the linkages of them all;

3) Several units can form a settlement by the same structure that the individual home uses. This settlement can also be one unit of the next level, and several such settlements constitute a larger settlement, and so on. An eco-unit settlement will show geometric growth.

Based on the "eco-unit settlement" approach, we designed the Lo Shu Square form of the hillside residential programme, which was awarded first prize in an architectural design competition in the Guangdong province that was held in 2006. It has become one of the programmes that are recommended by the government to those residents who are going to build houses themselves.

\subsection{Individual home}

The individual home is a section of a unit, as shown in Figs. 3-5. In addition to being able to use them separately, it can also form a unit with others through space enclosure and eco-technology linkages. Our ecological housing design has not only adopted the construction experience of the traditional houses locally, but is also equipped with rooftop solar water heaters, digesters, and other environmentally sound technologies.

\subsection{Forming unit}

\subsubsection{The use of the mountain terrain}

Most of the Chaoshan area is hilly terrain that is harder to be developed on than housing on flat land. Today, since most of the available flat land is exhausted, 


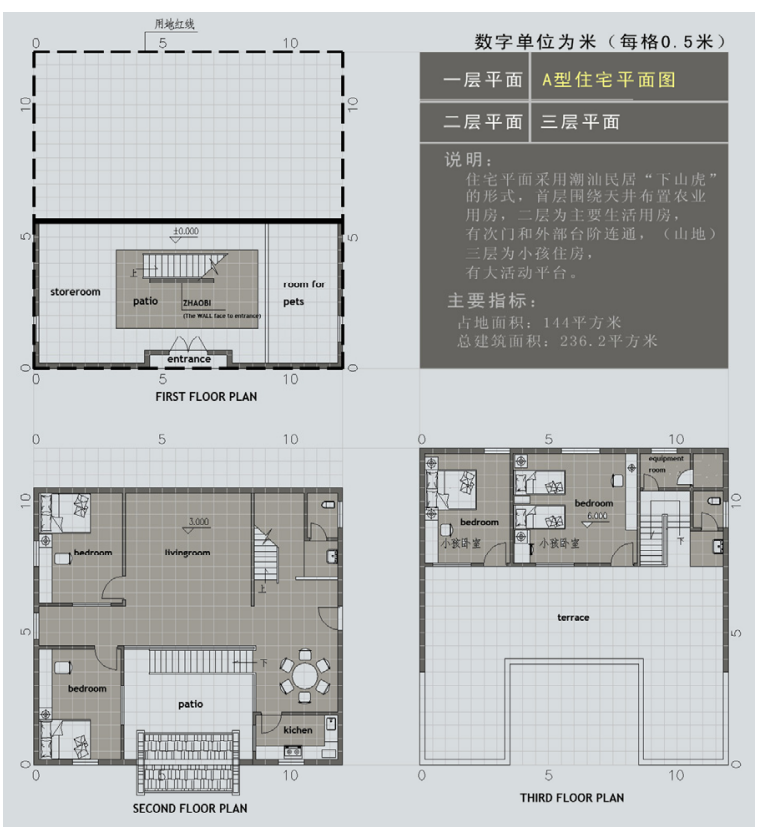

Figure 3: Residence floor plans.

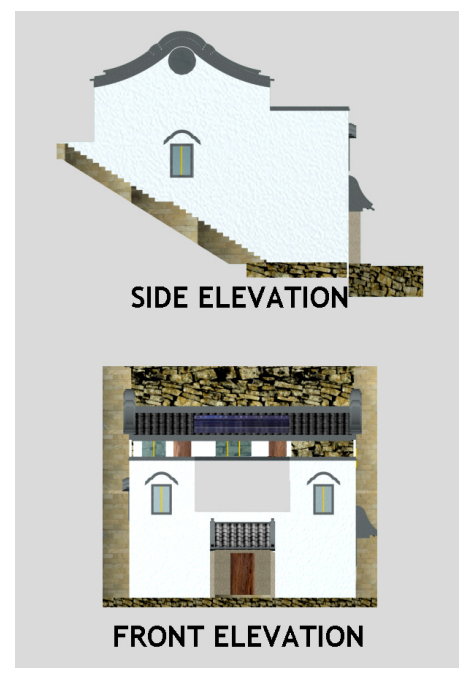

Figure 4: Residence elevations. 


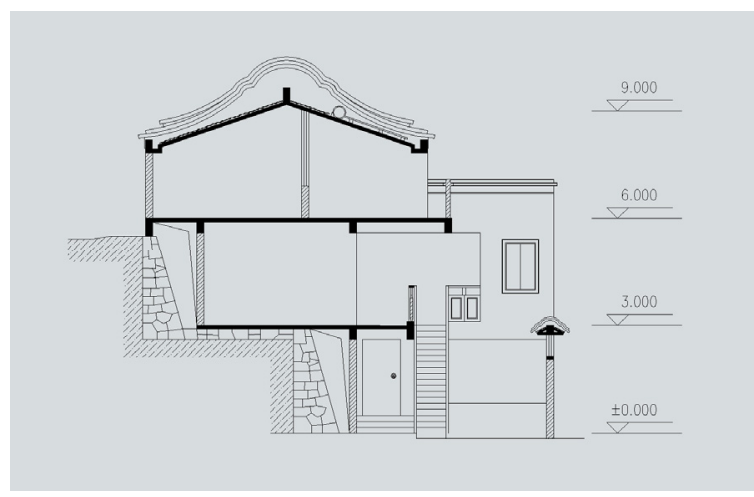

Figure 5: Residence section.

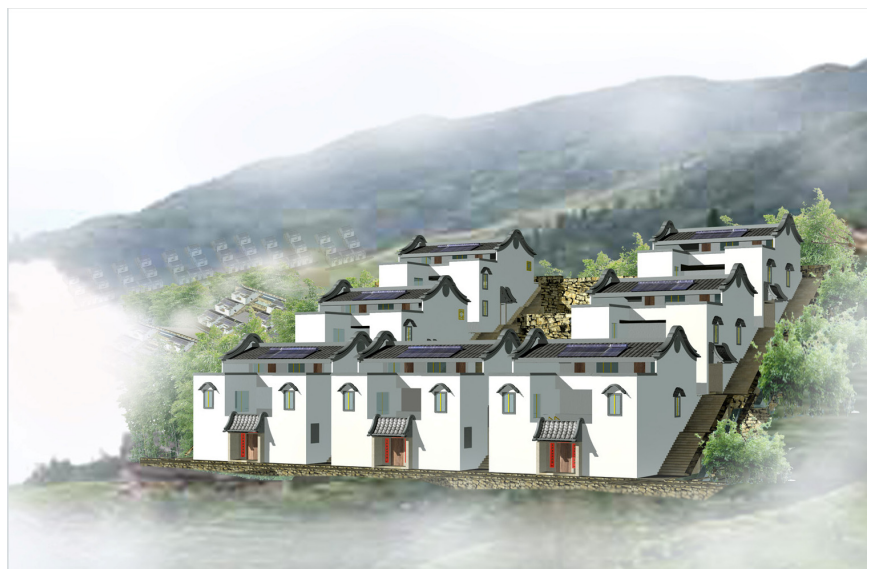

Figure 6: Hillside location.

the development and utilisation of the hillside is essential. Our proposed design uses the hillside to support a compact unit, as shown in Fig. 6.

\subsubsection{Lo Shu Square of the layout}

The overall layout of the design was inspired from the ancient Chinese game of chess that uses the pattern of "Lo Shu Square". Lo Shu Square is also used in Sudoku (a well-known game today) as shown in Fig. 7. The layout of the land is divided into nine equally sized rectangular grids in order to build houses and courtyards with pools that seem organic and compact. As shown in Fig. 8, the unit is arranged with seven houses, a courtyard, and a pool. The courtyard and pool can be the paradise for adults and children; meanwhile it is the place to use solar energy, breeding animals or plants, and collecting water to recycle. 


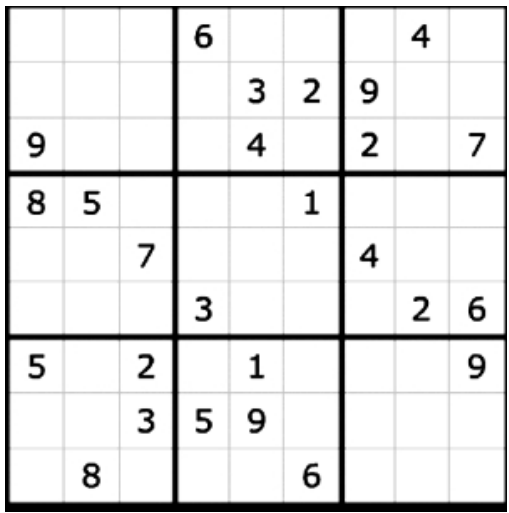

Figure 7: $\quad$ Sudoku in the form of Lo Shu Square.

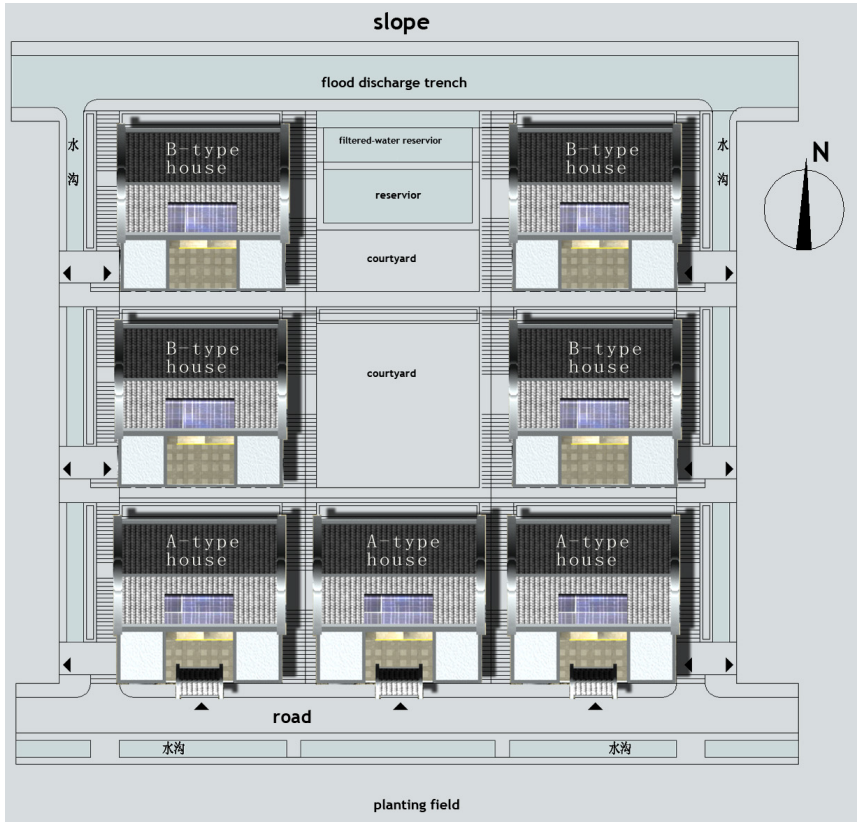

Figure 8: The unit in the form of Lo Shu Square.

\subsubsection{Benefits of an "eco-unit"}

The unit will help to conserve natural resources and reduce pollution by using the recommended eco-technologies. These eco-technologies include solar energy, rainwater collection, wastewater treatment, garbage classification placement, as well as animal and plant breeding (see Fig. 9). The people living in these settlements will share the benefits and costs so as to create an autogenous place. 


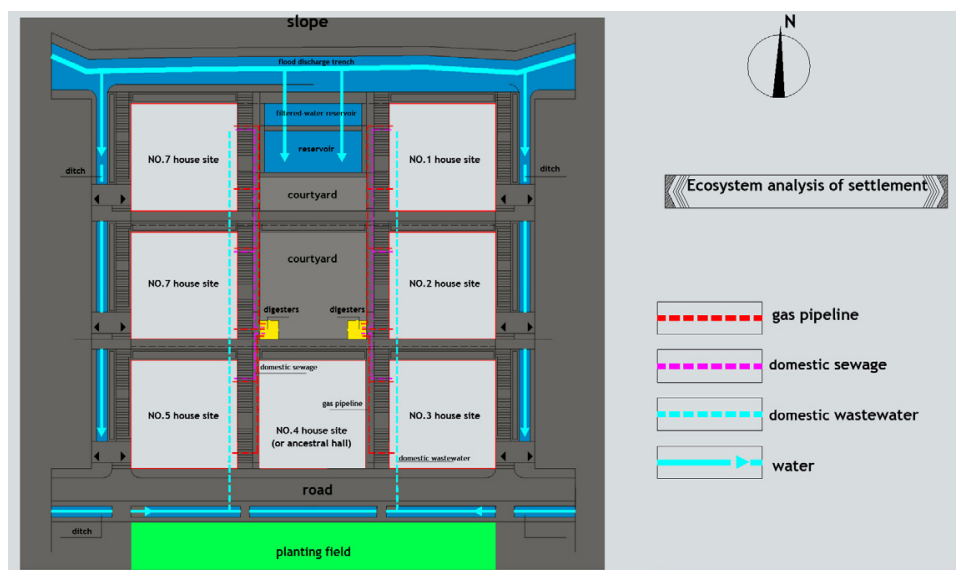

Figure 9: The use of eco-technology in the unit.

\section{Conclusions}

The imperative ecological architecture, which properly addresses global warming, the consequences of wasteful energy consumption, and the use of nonrenewable resources, has been established. In order to achieve eco-architecture in regions with a unique culture, our designs need to adapt to the vernacular culture. The dwelling design is based on the model of an "eco-unit settlement" that is adapted to the vernacular culture by forming a combination of cultural characteristics with eco-tech. Although our "eco-unit settlement" programme is only an attempt for the Chaoshan area on hillside conditions, we must also face various other problems that require more solutions in reality, if we are going to move in the right direction for progress.

\section{Reference}

[1] Fang, Z.Y., The Geographical Climatology Research of The Chinese Traditional Ethnic group, Journal of Beijing University of Civil Engineering and Architecture, 2000; (01); 50-59 (in Chinese).

[2] Lin, K.L., The traditional houses in the Chaoshan area, Shantou University Press: Shantou, China, 2004.

[3] Shantou Municipal Bureau of Land and Resources, www.stgtj.gov.cn/

[4] Cao, W., The search for a new concept of ecological communities and their living environment, Architectural Journal, 2002; (09); 59-61(in Chinese).

[5] Chen, Y.T., The architect's other ideological emancipation - on the "open architecture" concept, Architectural Design Management, 2008; (05); 4647(in Chinese).

[6] Zhen, Z. \& Liu, G., The ecological planning and design for human habitation in the small town of Fujian, Architectural Journal, 2007; (11); 2628 (in Chinese). 